\section{Regurgitation through a laryngeal mask}

To the Editor:

Dr. Brain ${ }^{l}$ advised to watch for fluid that may suddenly appear inside the laryngeal mask for early warning of regurgitation. It is somewhat difficult to see the busy anaesthetist looking at the laryngeal mask all the time waiting for regurgitation. I would like to suggest the paratracheal audible respiratory monitor ${ }^{2,3}$ to do this job or, if you don't have one, attach a stethoscope to the patient's paratracheal area ... but in this case you should also be attached to it.

\author{
Joseph Eldor MD \\ Department of Anesthesia \\ Misgav Ladach General Hospital \\ P.O. Box 12142 \\ Jerusalem 91120 , Israel
}

\section{REFERENCES}

1 Brain $A I J$. Regurgitation and the laryngeal mask. Can J Anaesth 1992; 39: 743-4.

2 Eldor J, Adler D, Mahler Y, Davidson JJ. Para-tracheal audible respiratory monitor (PTARM). Can J Anaesth 1987; 34: 328.

3 Eldor J, Guedj P, Adler D, Mahler Y, Olshwang D. Un appareil pour la surveillance peranesthesique de la ventilation: le moniteur pretracheal. Ann Fr Anesth Reanim 1990; 9: 9-98.

\section{$R E P L Y$}

Fluid seen in the transparent tube of the laryngeal mask (LM) during the course of anaesthesia should be regarded as evidence that regurgitation is actually occurring (alert anaesthetist) or has already occurred (no so alert anaesthetist), but not that it is about to occur. A paratracheal audible respiratory monitor may indeed provide such a warning, but this is not because regurgitation is easier to hear than to see. In fact, it may help detect signs of inadequate anaesthesia, such as sudden cessation of breath sounds in spontaneously breathing patients, or sounds of gas leakage at the mask-to-larynx seal in ventilated patients. In the former, high intrathoracic negative pressures may be transmitted to the oesophagus and in the latter gas may be diverted into the stomach. Both can lead to regurgitation, but both can be prevented by carefully matching the ar iesthetic requirement to the level of surgical stimulation throug.tout the procedure. It is the exercise of this fundamental anaesthetic responsibility which, hopefully, is keeping Dr. Eldor's anaesthetist so busy.

Dr. A.I.J. Brain

Department of Anaesthesia

Northwick Park Hospital

Harrow, Middlesex

England HAI 3UJ

\section{Tracheal intubation and cervical injury}

To the Editor:

In recent correspondence Drummond ' and Crosby ${ }^{2}$ seem at cross purposes because their concerns are for different case scenarios. Drummond asks about a case for elective surgery and Crosby ${ }^{2}$ refers to head injury, urgency, ventilation and resuscitation. Differing circumstances, priorities, indications and justifications would seem to apply between unconsciousness/emergency/resuscitation/airway obstruction as against awake/elective/surgery. One of Drummond's worries I believe, with reason, is that the employment of modes of management applicable to the particular conditions of one area may be taken as arguments for their use in other areas with quite different conditions, or even for their blanket use.

Drummond very rightly points out that Crosby $^{3}$ did not describe how the levels of spinal fractures in his cases related to the distribution of usage of (i) awake vs general anaesthesia intubation and (ii) the various intubation methods employed. In their letters Crosby ${ }^{2}$ utilizes the term "airway" five times, for each of which "intubation" could be substituted and is probably meant, and Drummond not once. The need to limit or avoid head and neck movements in the injured cervical spine patient may increase difficulty of laryngoscopy/intubation. This is generally recognized and highly emphasized. What seems to get forgotten or ignored is that it also compromises the potential for airway control and maintenance after general anaesthesia is induced.

Most of us have experienced an instance of mask general anaesthesia, in an apparently normal patient possessing full unrestricted head and neck movements where keeping an unobstructed airway proved difficult or even impossible with a need to relieve by endotracheal intubation. Conversely if general anaesthesia ( \pm muscle relaxants) is induced under conditions of excluded head and neck movements how can it be certain that the airway will remain or can be kept unobstructed and oxygenation continued? If intubation proves difficult or fails and further oxygenation is needed what then? Does one move the head and neck? How much movement does one make to acquire, what can't even so be guaranteed, a clear airway and oxygenation? It is fair to say that the approach takes the airway for granted and depends on the intubation being straightforward and successful.

The injured cervical spine patient should be regarded, and managed, as a combined compromised airway and difficult laryngoscopy situation. The anaesthesia preceding intubation should rather be based on airway considerations and not on intubation conceptions. The air- 